\title{
Bioprocess modelling for the design and optimization of lignocellulosic biomass fermentation
}

\author{
Pornkamol Unrean*
}

\begin{abstract}
Lignocellulosic feedstocks, which are currently under-exploited, can be used for the production of biofuels, such as ethanol, and for biorefinery applications to produce a variety of value-added products. Although bioconversion of lignocellulose by microbial or yeast fermentation have been reported, efficient and economical lignocellulosic fermentation process is still a challenge due to multiple process parameters involved for bioprocess design, optimization and scale-up. Bioprocess modelling strategies have been proven effective for achieving high-production process* efficiency in yield, productivity or titer of desired product. Several types of bioprocess modelling for lignocellulosic application have been developed and successfully validated as a promising alternative for rapid design, optimization and scaling up of biomass-based process. This review aims to summarize the important development of bioprocess modelling for lignocellulosic bioprocess applications towards the success of biorefineries and bio-based economy. In particular, we discuss modelling relevant to lignocellulosic bioprocess including cell modelling based on kinetics, stoichiometry and integrative approaches and fermentation kinetic modelling for process performance assessment. An overview of these modelling approaches and their application for systematic design of efficient and economical lignocellulose-based bioprocesses are given.
\end{abstract}

Keywords: Lignocellulosic bioprocess, Systematic process optimization, Integrative cell modelling, Fermentation model, Process integration

\section{Background}

Low-priced, abundant and renewable lignocellulosic biomass has become an attractive alternative feedstock to significantly supplement corn and starch as a fermentation feedstock for bio-based production (FitzPatrick et al. 2010; Kircher 2012). These substrates can be obtained from agricultural, industrial and municipal solid wastes and forestry residues. The use of lignocellulose resources for the production of biochemicals and biofuels is considered as cost-effective and environmentally sustainable serving bio-based economy (Binod et al. 2010; Lopes 2015). The optimization of the technology and scale-up for lignocellulosic bioprocess is rapidly developing by

\footnotetext{
*Correspondence: pornkamol.unr@biotec.or.th

National Center for Genetic Engineering and Biotechnology (BIOTEC), National Science and Technology Development Agency (NSTDA), 113 Thailand Science Park Phahonyothin Road, Klong Nueng, Klong Luang, Pathum Thani 12120, Thailand
}

several biotech companies and pilot plants in Europe and the US. Bioconversion of lignocellulose to bioproducts requires lignocellulosic biomass to be hydrolysed in order to generate monomeric sugars for the fermentation step. Hydrolysis of lignocellulose is usually achieved by means of a thermal and/or chemical pretreatment followed by enzyme hydrolysis. Many studies have demonstrated the feasible production of bioproducts by both bacteria (e.g. Zymomonas mobilis, Escherichia coli) and yeasts (e.g. Saccharomyces cerevisiae, Scheffersomyces stipitis) using lignocellulosic feedstock (Geddes et al. 2015; Zhang and Lynd 2010; Van Zyl et al. 2007; Unrean and Nguyen 2012). However, several challenges remain for achieving the efficient hydrolysis and fermentation of lignocellulose. Studying enzymatic and chemical hydrolysis of lignocellulosic biomass based on experimental and modelling approaches has been extensively reviewed elsewhere (Van Dyk and Pletschke 2012; Bansal et al.

\section{Springer}

C 2016 Unrean. This article is distributed under the terms of the Creative Commons Attribution 4.0 International License (http:// creativecommons.org/licenses/by/4.0/, which permits unrestricted use, distribution, and reproduction in any medium, provided you give appropriate credit to the original author(s) and the source, provide a link to the Creative Commons license, and indicate if changes were made. 
2009; Meng and Ragauskas 2014; Hodge et al. 2009; Geddes et al. 2010; Sun and Cheng 2002). Hence, this review focuses on the fermentation step of lignocellulosic bioprocess based upon integrative cell and fermentation kinetic modelling framework.

One of the challenges of lignocellulose fermentation is the presence of sugar mixture (mainly glucose and xylose) released during the pretreatment and enzyme hydrolysis of lignocellulosic materials. From an economic point of view, these sugars must be efficiently fermented by organisms into desired product (Bera et al. 2010; Konishi et al. 2015; Unrean and Srienc 2010). The fluctuation of sugar composition, $30-50 \%$ and $10-25 \%$ of dry weight for glucose and xylose content, respectively, in different biomass feedstock strongly affects fermentation performance since an organism may not be able to optimally adjust its fermentation capacity to match with the change in sugar composition resulting in long fermentation time. A culture system that is able to handle the variation of sugar composition and efficiently ferment the sugar mixture is therefore required in order to meet the technical and economic requirements of industrial lignocellulosebased process. Another challenge for lignocellulosic fermentation is the presence of inhibitory substances (such as acetic acid and furans) generated during the pretreatment strongly inhibiting growth and fermentation performance of fermenting organism (Almeida et al. 2007; Allen et al. 2010; Klinke et al. 2004). These inhibitors are significant hurdles for the implementation of largescale lignocellulose-based bioprocess. Removal of the inhibitors by physical and chemical means significantly adds to the overall process cost and causes loss of sugars (Liu and Blaschek 2010). Therefore, the use of inhibitortolerant microorganisms in the fermentation or the use of optimized process configuration to minimize inhibitory effects is required to improve process efficiency. The development of inhibitor-tolerant cell factory is previously reviewed by Liu $(2006,2011)$ describing the mechanisms of action of known inhibitors as well as metabolic and evolutionary engineering strategies for tolerant strain development. Thus, this review focuses on fermentation process configuration to overcome inhibition issue caused by the inhibitors and fermentative end products. Moreover, problems with viscosity and partial insolubility of lignocellulosic biomass can cause poor mixing and limited mass and heat transfer especially at high solid operation of fermentation process. Design of fed-batch process configuration with sufficient mixing is required to improve process efficiency (Nguyen et al. 2015; Geddes et al. 2010; Unrean et al. 2015).

Hence, this review article discusses the development of cell and bioprocess modelling to provide a comprehensive update of the model-based approach for the design, optimization and scale-up of biomass-based processes. Specific modelling strategies for optimizing fermentation control in lignocellulosic bioprocess based on integrative cell modelling and fermentation kinetics are discussed.

\section{Cell modelling for growth and fermentation of lignocellulosic hydrolysate}

Different type of cell modelling that is relevant to cell growth and fermentation of lignocellulosic bioprocesses is explored as follows:

\section{Monod cell growth kinetics}

An unsegregated and unstructured model based on Monod kinetic has been the most commonly used model to describe the overall cell growth and fermentation in batch, fed-batch or continuous lignocellulosic biomass processes. The Monod's cell modelling which considers cell growth as one, single reaction is typically composed of the kinetics of (1) cell growth determined by limiting substrate (i.e. glucose or xylose present in biomass feedstock), and (2) cell death due to the endogenous metabolism as well as toxicity caused by end product or inhibitors (e.g. furfural, HMF or acetic acid) present in hydrolysates. A generalized Monod's cell growth equation with competitive and non-competitive inhibition of inhibitors and cell growth inhibition of end product is

Specific cell growth rate:

$$
\begin{aligned}
\mu_{S_{i}}= & \mu_{\max , S_{\mathrm{i}}}\left(\frac{C_{S_{i}}}{K_{\mathrm{mu}, S_{i}}\left(1+I_{i} / K_{i}\right)+C_{S_{i}}}\right) \\
& \prod_{j}\left(\frac{1}{1+I_{j} / K_{j}}\right)\left(1-\frac{C_{\mathrm{P}}}{C_{\mathrm{P}, \max }}\right)^{n} .
\end{aligned}
$$

In addition, cell death kinetics is typically applied to prevent an over-prediction of cell viability in lignocellulosic process (Zhang et al. 2009a, b). Both cell death rate caused by end product and cultivation temperature can be described by Arrhenius-type kinetics (Mutturi and Lidén 2014). Furthermore, two distinct population of cells: one is active population able to replicate, Type I cell, and another is stalled population unable to replicate due to toxicity of inhibitors, Type II cell, can also be included in the cell growth model (Wang et al. 2014). The predicted cell death rates due to endogenous metabolism, temperature, end product and toxicity of inhibitors present in hydrolysate are given as follows:

Specific cell death rate:

$$
K_{\mathrm{D}}=\sum_{S_{i}}\left(m_{S_{i}} Y_{X, S_{i}}^{\max }\right) .
$$

Temperature-dependent cell death rate:

$$
K_{\mathrm{DT}}=A \exp (-E / R T) .
$$


Product-dependent cell death rate:

$$
K_{\text {De }}=a \exp \left(b C_{\mathrm{P}}\right) .
$$

Transformation rate from type I to type II cell:

$$
K_{\text {trf }}=k_{\mathrm{T}}+\frac{v_{\mathrm{T}}^{\max } I_{k}^{\mathrm{H}}}{k_{\mathrm{T}}^{\mathrm{H}}+I_{k}^{\mathrm{H}}} .
$$

The generalized equation describing cell growth can then be generated by combining Eqs. (1, 2, 3, 4 and 5):

$$
\frac{\mathrm{d} X}{\mathrm{~d} t}=\left(\sum_{S_{i}} \mu_{S_{i}}-K_{\mathrm{D}}-K_{\mathrm{DT}}-K_{\mathrm{De}}-K_{\mathrm{trf}}\right) X-D X .
$$

This equation is commonly applied for predicting cell growth during the fermentation of lignocellulosic hydrolysate.

\section{Stoichiometric metabolic model}

Cell growth can also been simulated based on a steadystate flux balance model which solves the stoichiometric mass balance of metabolic reaction network within cell. The model allows for quantification of carbon flux occurring within the cell by coupling extracellular fluxes for cell growth, substrate uptake and product secretion with the intracellular flux distribution in matrix form:

Stoichiometric flux balance:

$$
\underline{S} \cdot \underline{q}=\underline{-} \text {. }
$$

The most common mathematical tool used for solving these balance equations is flux balance analysis (FBA). The reader is referred to Maarleveld et al. (2013) for the thorough review of concept and application of this computation tool. Briefly, FBA yields a single flux solution that satisfies specified objective and constraints based on linear program (LP) optimization. The commonly used objectives are as follows:

Objective : $\max \mu, q_{P}$ or $q_{A T P}$

Subject to : $q_{\min } \leq q \leq q_{\max }$

$$
\begin{aligned}
& J_{i}=J_{i}, i \in E \\
& J_{i}=0, i \in N \\
& J_{i, \min } \leq J_{i} \leq J_{i, \max }, i \in M
\end{aligned}
$$

The stoichiometry metabolic model has been utilized to study the response of cell metabolism to different environmental and genetic perturbations or different stresses caused by inhibitors during lignocellulosic fermentation process (Heer et al. 2009; Hanly and Henson 2014). By constraining fluxes associated with corresponding genes, the stoichiometric model can be applied to guide genetic engineering for increasing production of biorefinery products such as ethanol, malic acid and succinic acid (Pizarro et al. 2007; Oberhardt et al. 2009) as well as to aid process development, optimization and scale-up (Baart et al. 2007). Integration of stoichiometric metabolic model with dynamic model, regulatory and signalling network in the future could significantly increase the usefulness of the model for guiding cell engineering and optimizing lignocellulosic bioprocesses.

\section{Fermentation kinetic model}

Kinetic model to describe fermentation profile of lignocellulosic hydrolysate can be developed by taking into account growth-limiting factor such as sugar and/or nitrogen content, product titer and temperature influenced fermentation process. The proposed lignocellulosic fermentation kinetic model typically comprises (1) the sugar uptake equation and (2) the fermentation equation of secreting products. Sugar uptake model following Michaelis-Menten kinetics considers the uptake rate of hexose and pentose sugars (e.g. glucose or xylose) for cell growth, product synthesis and for maintenance process, the competitive inhibition between hexoses for each transporter (Pizarro et al. 2007) and the non-competitive inhibition between hexoses and pentoses (Zhang et al. 2009a, b). The non-competitive inhibition of sugar transport caused by increasing concentration of end product and by the presence of inhibitors (e.g. acetic acid, furfural or HMF) are also commonly included in the model to capture the adverse effects of these compounds on sugar fermentation (Hanly and Henson 2014). A generalized kinetics of sugar uptake is

Specific sugar uptake rate:

$$
q_{S_{i}}=\left(\frac{V_{\max , S_{\mathrm{i}}} C_{S_{i}}}{K_{m, S_{i}}+C_{S_{i}}}\right) \prod_{S_{j}}\left(\frac{1}{1+C_{S_{j}} / K_{S_{j}}}\right) \prod_{j}\left(\frac{1}{1+I_{j} / K_{j}}\right) .
$$

The balance equation of sugar during lignocellulosic hydrolysate is as follows:

Balance equation of sugar:

$$
\frac{\mathrm{d} C_{S_{i}}}{\mathrm{~d} t}=-q_{S_{i}} X-m_{S_{i}} X+D\left(C_{S_{i}} \text {, feed }-C_{S_{i}}\right) .
$$

Some yeast cells such as $S$. cerevisiae have ability to convert inhibitors (e.g. furfural or HMF) present in lignocellulosic hydrolysate into less toxic compounds. Thus, kinetics of inhibitor conversion should also be included when describing cell growth and fermentation. The conversion kinetics of inhibitors can be defined similarly to that of sugar uptake. A model developed by Hanly and Henson (2014) has described the detoxification of furfural and HMF from hydrolysate media by $S$. cerevisiae. The kinetics of fermentation describing growth-associated production based on Monod kinetics 
and non-growth-associated production for fermentation products can be written in a general form as follows:

Secreting products:

$$
\begin{aligned}
& \frac{\mathrm{d} C_{P_{i}}}{\mathrm{~d} t}=q_{P_{i}} X-D C_{P_{i}} \\
& q_{P_{i}}=\left(\frac{V_{\max , \mathrm{P}_{\mathrm{i}}} C_{S_{i}}}{K_{P_{i}}+C_{S_{i}}}\right)=Y_{P_{i}, S_{i}}\left(q_{S_{i}}+m_{S_{i}}\right) .
\end{aligned}
$$

Combining cell growth and fermentation kinetic model then permits the prediction of time profiles for the production of bioproducts, such as ethanol, during lignocellulosic hydrolysate fermentation.

\section{Integrative dynamic model for cell growth and fermentation}

Most modelling frameworks describing cell growth and fermentation are based on a simple unstructured Monod kinetic model or a steady-state stoichiometric flux balance model. Integrative dynamic model framework has recently been proposed through incorporation of kinetic model and stoichiometric metabolic model for the prediction of dynamic whole-cell metabolism as the culture environment dynamically changes with time. Integrative dynamic model allows the thorough studies of a dynamic interaction of cell metabolism occurring during culture environment changes or genetic alternation by predicting optimal metabolic flux distribution at each instant time throughout the process. Such model may enable an expanded platform to design process or genetic modification candidates that may enhance the efficiency in batch or fed-batch of lignocellulosic bioprocesses. Two types of integrative dynamic model capable of simulating dynamics of cell growth and fermentation in batch or fed-batch fermentation of lignocellulosic biomass have been developed: (1) dynamic flux balance model and (2) cybernetic model.

\section{Dynamic flux balance model}

Concept of dynamic flux balance analysis (dFBA) is relied on a flux balance stoichiometric network in combination with kinetic model describing cell growth and fermentation as illustrated in Fig. 1. First, the dynamic model utilizes kinetic equations to predict the substrate uptakes and additional flux constraints which are then used as inputs for the stoichiometric model analysis. The outputs of the flux balance model are the predicted specific rate of substrate and product (biomass and end product). The computed consumption and production rates based on flux balance are fed into the dynamic mass balance model, which are differential balance equations describing the concentration of the extracellular metabolites considered in the model. The dynamic mass balance is solved numerically to calculate time profiles of substrate and product in the fermentation process. The dFBA model has been used to predict cell growth and fermentation profiles in response to nitrogen source, culture temperature, inhibitory compounds (e.g. furfural, HMF) and ethanol toxicity in batch and fed-batch fermentation of lignocellulosic hydrolysates (Sainz et al. 2003; Pizarro et al. 2007; Hjersted and Henson 2006; Hanly and Henson 2014; Unrean and Franzen 2015; Unrean et al. 2015). In addition, the dFBA model can accurately predict the dynamic effects of genetic alternations and regulatory processes on the production performance (Pizarro et al. 2007; Lee et al. 2008). Thus, dFBA model proves useful for evaluation of the dynamic interactions between the cell metabolism and its changing environment in batch

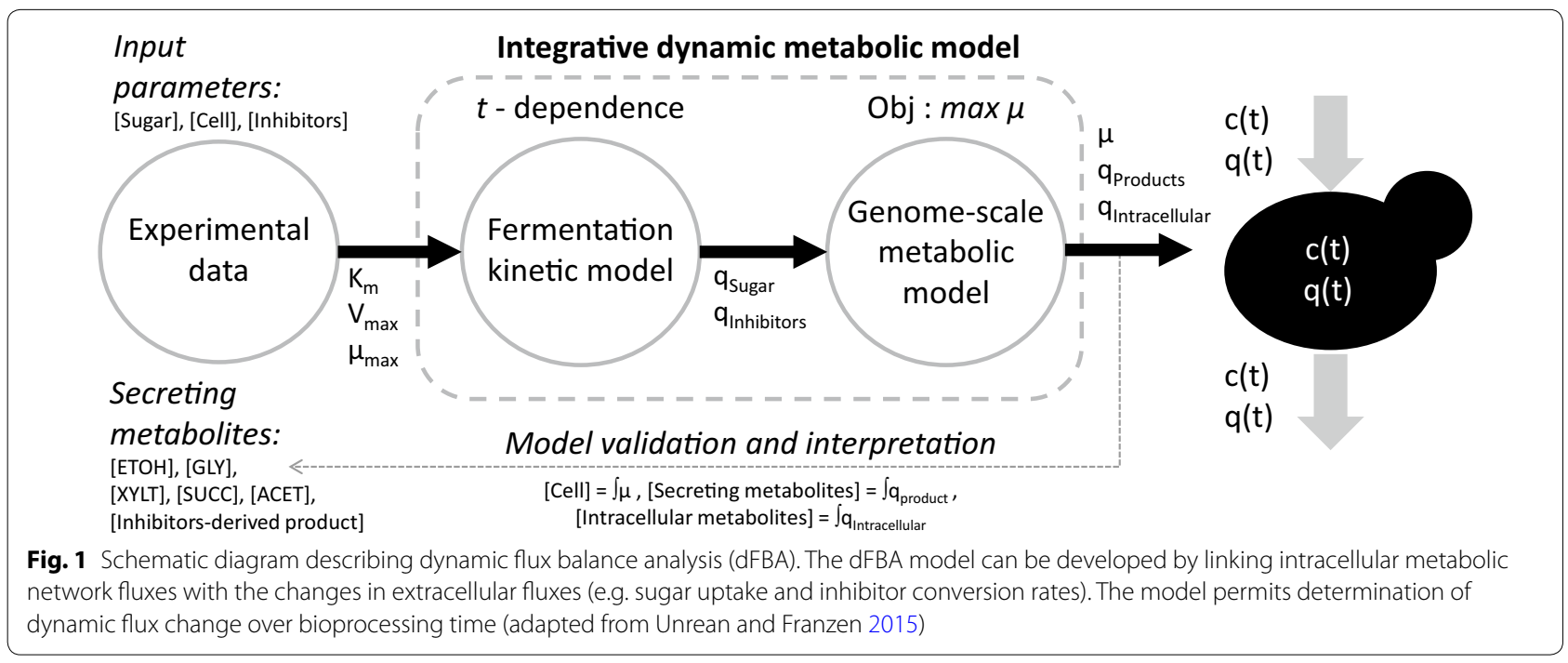


and fed-batch fermentation which could lead to a better design of cell and fermentation conditions in lignocellulosic process.

\section{Cybernatic model}

Cybernetic modeling framework is based on the incorporation of internal dynamics of simplified regulated metabolic network of cell and the effects of external environment (Murthy et al. 2012). Similar to dFBA model, the cybernetic model can be divided into two distinct but interlinked models. The first model determines reaction rates of cybernetic metabolic network model consisting of simplified catabolic and anabolic pathways that produce energy, catabolic and anabolic precursors necessary for cell growth and fermentation. These pathways are optimally utilized by cell for maximizing cell growth. The second model determines kinetics for cell growth, substrate uptake and product secretion based on the metabolite balance equations. The cybernetic model is typically described by set of equations for reaction rates following Monod kinetics by assuming to vary directly with the relative enzyme concentration and to exhibit saturation dependence on all substrates.

Reaction rate expression:

$$
r_{i}=k_{i} \varepsilon_{i} \prod_{j}\left(\frac{1}{1+K_{m_{j}} / C_{m_{j}}}\right) .
$$

The enzyme balance equation is given by

Enzyme balance:

$$
\frac{\mathrm{d} e_{k}}{\mathrm{~d} t}=r_{e_{k}}-\left(\beta_{k}+\mu\right) e_{k}
$$

The balance equations for cell growth, substrate, product and intracellular metabolite can be described as follows:

Cell growth:

$$
\frac{\mathrm{d} X}{\mathrm{~d} t}=\left(\sum_{i} r_{i} v_{i}\right) X-D X .
$$

Extracellular metabolite:

$$
\frac{\mathrm{d} C_{\text {mexj }}}{\mathrm{d} t}=\left(\sum_{i} r_{i} v_{i}\right) X-D\left(C_{\text {mexj feed }}-C_{\text {mexj }}\right) .
$$

Intracellular metabolite:

$$
\frac{\mathrm{d} C_{m_{j}}}{\mathrm{~d} t}=\sum_{i} r_{i} v_{i}-\mu_{S_{i}} C_{m_{j}}
$$

The cybernetic modelling approach has been used to accurately simulate yeast cell growth, ethanol fermentation and energy consumption in batch, fed-batch and continuous fermentation of lignocellulosic biomass (Straight and Ramakrishna 1994; Ko et al. 2010; Murthy et al. 2012).

\section{Model-based process design and optimization Cell consortium model for optimizing co-culture fermentation}

The process using cell consortia holds promise for a better exploitation of individual species capabilities leading to an efficient fermentation of pentose and hexose sugars that compose lignocellulosic biomass. A mixture of multiple substrate-selective microbial or yeast strains is expected to act in concert to simultaneously uptake pentose and hexose sugars and efficiently convert to value-added bioproducts (Suriyachai et al. 2013; Henson and Hanly 2014). Several studies have developed cell consortium model based on cell growth, fermentation kinetic model and dynamic flux balance model to study the capability of co-culture system and to optimize cell growth and mixed sugar fermentation performance by co-culture (Unrean and Srienc 2010; Unrean and Khajeeram 2015; Hanly and Henson 2013). Using the co-culture of multiple strains enhances ethanol titer, production rate, shorten fermentation time, and reduce process costs making the co-culture process a promising technology for industrial applications (Chen 2011; Wan et al. 2012; Yadav et al. 2011; Li et al. 2011; Hickert et al. 2013). The dynamic co-culture model has been applied to optimize the inoculum cell concentration and aeration level that maximized fermentation process efficiency (Unrean and Srienc 2010; Hanly and Henson 2013). Co-culture model has also been used to predict the optimal relative cell ratio of each strain that yields simultaneous consumption of different sugar mixture with minimal fermentation time enabling improved productivity and less production cost (Hanly et al. 2012; Unrean and Khajeeram 2015). The co-culture model also demonstrates the flexibility of the cell consortia for optimally handling any sugar mixture available in different biomass feedstock. Additionally, Hanly and Henson (2013) applied the cell consortium modelling strategy for predicting targeted gene manipulation in the xylose-fermenting yeast cell in order to further improve ethanol fermentation by co-culture. The cell consortium modelling framework could, therefore, provide strategies for rapid process optimization of the multiple-strain culture by optimally adjusting each strain distribution based on the model prediction to match with varying sugar composition in lignocellulosic biomass feedstock for efficient and sustainable production of bioproducts.

\section{Fed-batch lignocellulosic bioprocess optimization}

Fed-batch cultivation strategy by controlling the substrate feeding can be applied (1) to overcome inhibitory 
effects by maintaining the inhibitors at low concentrations, (2) to avoid accumulation of undesired byproducts caused by overflow metabolism and (3) to ensure a balanced feeding of mixed hexose and pentose sugar available in biomass feedstock for achieving high yield, titer and productivity of the desired product (Abdel-Rahman et al. 2015; Rudolf et al. 2007; Petersson and Lidén 2007; Johnsson et al. 2013). A kinetic model based upon a system of linear differential equations can be formulated to design and optimize various process configurations such as batch and fed-batch process for efficient fermentation of biomass-derived sugars. The model-based process optimization was demonstrated in designing feed strategy with optimal specific cell growth rate of fed-batch for efficient mixed glucose-xylose fermentation (Unrean and Nguyen 2012). The optimized batch with cell recycle or with in situ ethanol removal was also simulated based on the kinetic model (Slininger et al. 2014). Besides application of the integrative dynamic model to study whole-cell metabolism during batch and fed-batch processes, the modeling approach can be used for in silico determination of the optimal operating conditions, such as feed rate or feed medium composition, for fed-batch fermentation of lignocellulosic hydrolysate (Unrean and Franzen 2015).

Coupling cell and fermentation kinetic model with enzyme hydrolysis model permits the prediction of dynamic cell growth and fermentation during simultaneous saccharification and fermentation (SSF) process.
The fed-batch SSF offers several advantages including less water consumption, lower production cost through the reduced number and size of required equipment and utility as well as minimized negative effects of inhibitors present in lignocellulosic hydrolysate (Olofsson et al. 2008; Mohagheghi and Schell 2010; Koppram et al. 2014). An SSF modelling approach is a useful guiding tool for rational design of the optimal feed profiles of solid substrate, enzyme and yeast cell in fed-batch SSF to avoid poor mass and heat transfer caused by high viscosity and to maximize process efficiency, thereby meeting the technical and economic requirement of the lignocellulosic biomass process (Zhang et al. 2010; Zhao et al. 2013; Huang et al. 2014). Several mechanistic models for SSF have been previously developed which describe kinetics of enzyme hydrolysis and yeast cell fermentation (Van Zyl et al. 2011; Morales-Rodriguez et al. 2011; Mutturi and Lidén 2014; Wang et al. 2014). The SSF model comprises two interlinked models, the enzyme hydrolysis model providing the quantitative analysis of the enzyme kinetics and the fermentation kinetic model describing kinetics of cell growth and sugar fermentation by organisms. The integrative SSF model has also been developed which integrates the enzyme hydrolysis model with the dynamic cell metabolic model to quantitatively capture the dynamic responses of enzyme and cell metabolism with changing culture environment (e.g. substrates, inhibitors and end products) during SSF. Figure 2 represents

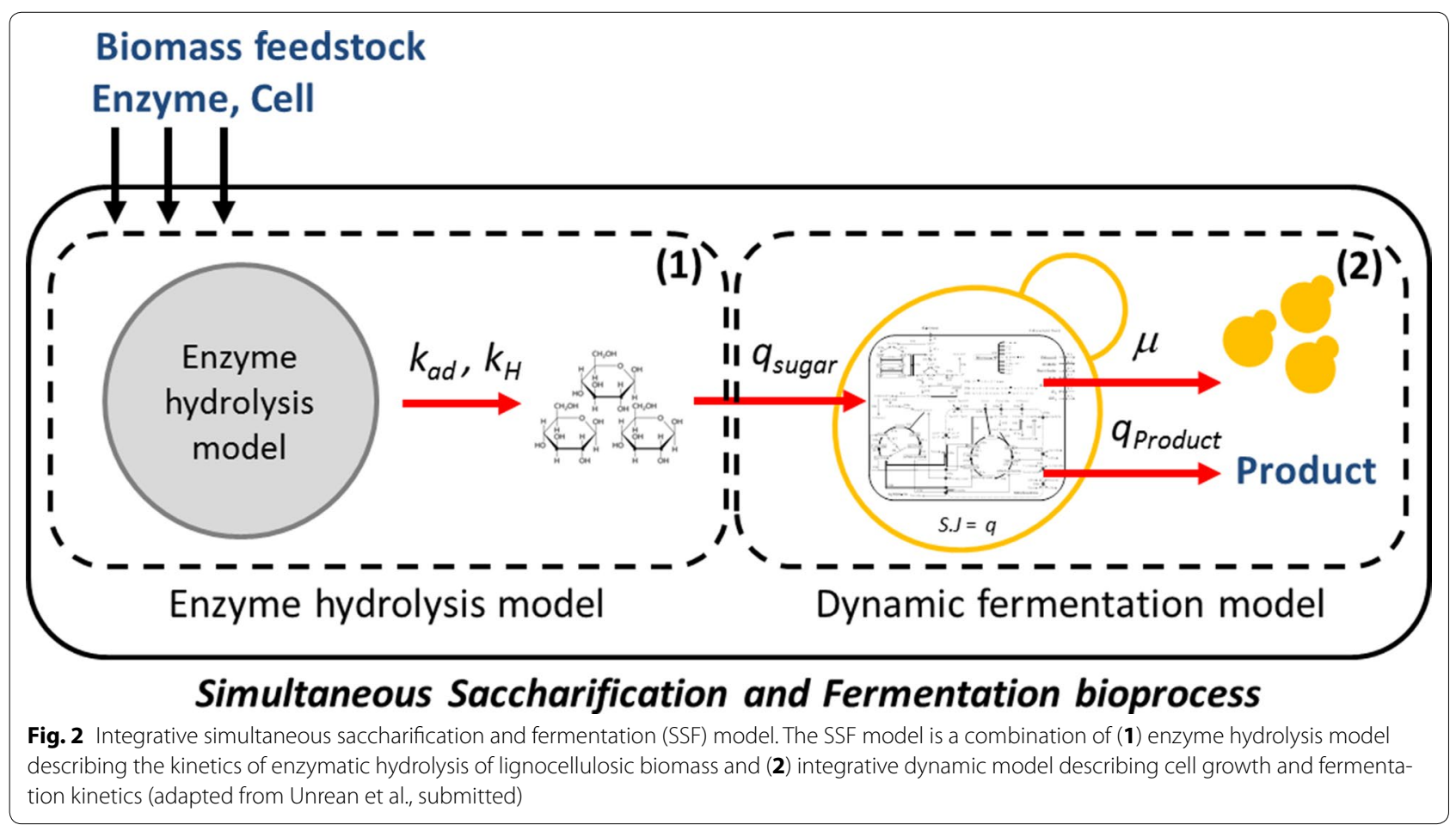


schematic diagram describing integrative SSF model. This integrative SSF modelling approach describing the enzyme kinetics together with the dynamics, timedependence involved in the cell metabolism is capable of accurately predicting ethanol fermentation profiles by $S$. cerevisiae during SSF process. The model is considered a useful guiding tool for predicting fed-batch SSF process performance under various solid substrate, enzyme and yeast cell feed profiles permitting a systematic optimization of feeding strategies for efficient fed-batch SSF with maximized product yield, titer and productivity (Unrean et al. 2015).

\section{Future prospect}

The utilization of lignocellulosic feedstocks as substrate in bio-based processes has increased considerably in recent years for a sustainable development of bio-based economy. Design and optimization of lignocellulosic bioprocesses to improve yield, titer and productivity of desired bioproducts is key to the success of bioprocesses and biorefineries. Model-based bioprocess design and optimization appears as a promising approach that can be used, in combination with genetic engineering and fermentation control, to facilitate the systematic design and optimization efforts aimed at rapidly improving efficiency of lignocellulosic biomass process for the production of value-added products. Integrative cell and fermentation kinetic modelling can assist in designing fermentation strategies or identifying genetic modification candidates for enhanced lignocellulose-based bioprocess efficiency to meet the current technical and economical demand. However, the current models do not include the regulatory and signalling network or stress response mechanisms of the cell when being cultured in lignocellulosic hydrolysate which also play important roles in determining the process efficiency. Inclusion of high-throughput omics data to describe cellular regulation and genome-wide kinetics is a future trend to further improve the accuracy of the integrative modelling framework for lignocellulosic bioprocess design, optimization and scaling up.

\section{Nomenclature}

$C_{S_{i}} \quad$ concentration of sugar $S_{i}$

$C_{S_{j}} \quad$ concentration of sugar $S_{j}$

$C_{S_{i} \text {, feed }}$ concentration of sugar $S_{i}$ in feed media

$C_{P} \quad$ concentration of end product $P$

$C_{P, \max } \quad$ maximum concentration of end product $P$

$C_{m_{j}} \quad$ concentration of intracellular metabolite $m_{j}$

$C_{\text {mexj }} \quad$ concentration of extracellular metabolite $m_{e x, j}$

$C_{\text {mexj,feed }}$ concentration of metabolite $m_{e x, j}$ in feed media

$I_{i} \quad$ concentration of competitive inhibitor $i$

$I_{j} \quad$ concentration of non-competitive inhibitor $j$

$I_{k} \quad$ concentration of inhibitor $k$

$X \quad$ biomass concentration

$t \quad$ fermentation time

$\mu_{S_{i}} \quad$ specific cell growth rate

$\mu_{\max } S_{i} \quad$ maximum specific growth rate on sugar $S_{i}$

$D \quad$ dilution rate of continuous culture mode

$q \quad$ metabolite flux vector of enzymatic reaction

$q_{S_{i}} \quad$ specific uptake rate of sugar $S_{i}$

$q_{P_{i}} \quad$ specific production rate of product $P_{i}$

$q_{\mathrm{ATP}} \quad$ synthesis rate of ATP

$V_{\max }, S_{i} \quad$ maximum rate of sugar $S_{i}$ uptake

$V_{\max , P_{i}} \quad$ maximum specific production rate of product

$P_{i}$

$v_{\mathrm{T}}^{\max } \quad$ maximum specific transformation rate

$K_{m, S_{i}} \quad$ saturation constant of sugar $S_{i}$ uptake

$K_{S_{j}} \quad$ non-competitive inhibition rate constant of sugar $S_{j}$ on sugar $S_{i}$

$K_{\mathrm{mu}, S_{i}} \quad$ saturation constant for growth on sugar $S_{i}$

$K_{P_{i}} \quad$ saturation constant of product $P_{i}$

$K_{i} \quad$ competitive inhibition rate constant of inhibi-

tor $i$

$K_{j} \quad$ non-competitive inhibition rate constant of inhibitor $j$

$K_{\text {trf }} \quad$ specific transformation rate from type I to type II cells

$k_{\mathrm{T}} \quad$ inhibitor saturation constant of type I-type II cell transformation

$n \quad$ exponential constant of ethanol inhibition to growth on sugar $S_{i}$

$m_{S_{i}} \quad$ maintenance coefficient for growth on sugar $S_{i}$ $Y_{X, S_{i}}^{\max } \quad$ maximum cell yield on sugar $S_{i}$

$Y_{P_{i}}, S_{i} \quad$ yield of product $P_{i}$ based on consumed sugar $S_{i}$

$A \quad$ frequency factor for Arrhenius equation

E activation energy for Arrhenius equation

$\mathrm{T} \quad$ culture temperaturef

a ethanol death coefficient

$b \quad$ ethanol death rate constant

$H$ coefficient for cooperative transformation from type I to type II cells

$S \quad m$ by $n$ stoichiometric matrix of metabolite $m$ in enzymatic reaction $n$

$J \quad$ vector of accumulation and exchange rates

E set of intracellular metabolites with externally determined exchange flux

set of intracellular metabolites with no accumulation set of extracellular metabolites based on 


\begin{tabular}{|c|c|}
\hline \\
\hline & specific rate of reaction \\
\hline & radation of metabolite \\
\hline & synthesis rate of enzyme $k$ \\
\hline & rate constant of reaction $i$ \\
\hline & $\begin{array}{l}\text { relative concentration of enzyme catalysi } \\
\text { reaction } r_{i}\end{array}$ \\
\hline & saturation constant of metabolite $m_{j}$ \\
\hline & concentration of enzyme $k$ \\
\hline & first-order degradation constant of $\epsilon$ \\
\hline & cybernetic variable for activity of el \\
\hline
\end{tabular}

\section{Acknowledgements}

We greatly acknowledge Thailand Research Fund (Grant no. P-15-51025) and National Center for Genetic Engineering and Biotechnology, Thailand (Grant no. P-15-50042), for funding support.

\section{Competing interests}

The authors declare that they have no competing interests.

Received: 24 September 2015 Accepted: 16 December 2015

Published online: 04 January 2016

\section{References}

Abdel-Rahman MA, Xiao Y, Tashiro Y, Wang Y, Zendo T, Sakai K, Sonomoto K (2015) Fed-batch fermentation for enhanced lactic acid production from glucose/xylose mixture without carbon catabolite repression. J Biosci Bioeng 119:153-158

Allen SA, Clark W, McCaffery JM, Cai Z (2010) Furfural induces reactive oxygen species accumulation and cellular damage in Saccharomyces cerevisiae. Biotechnol Biofuels 3:2-12

Almeida JM, Modig T, Petersson A, Hahn-Hägerdal B (2007) Increased tolerance and conversion of inhibitors in lignocellulosic hydrolysates by Saccharomyces cerevisiae. J Chem Technol Biotechnol 82:340-349

Baart GJ, de Jong G, Philippi M, van't Riet K, van der Pol LA, Beuvery EC, Tramper J, Martens DE (2007) Scale-up for bulk production of vaccine against meningococcal disease. Vaccine 25:6399-6408

Bansal P, Hall M, Realff MJ, Lee JH, Bommarius AS (2009) Modeling cellulase kinetics on lignocellulosic substrates. Biotechnol Adv 27:833-848

Bera AK, Sedlak M, Khan A, Ho NW (2010) Establishment of L-arabinose fermentation in glucose/xylose co-fermenting recombinant Saccharomyces cerevisiae 424A(LNH-ST) by genetic engineering. Appl Microbiol Biotechnol 87:1803-1811

Binod P, Sindhu R, Singhania RR, Vikram S, Devi L, Nagalakshmi S, Kurien N, Sukumaran RK, Pandey A (2010) Bioethanol production from rice straw: an overview. Bioresour Technol 101:4767-4774

Chen Y (2011) Development and application of co-culture for ethanol production by co-fermentation of glucose and xylose: a systematic review. J Ind Microbiol Biotechnol 38:581-597

FitzPatrick M, Champagne P, Cunningham MF, Whitney RA (2010) A biorefinery processing perspective: treatment of lignocellulosic materials for the production of value-added products. Bioresour Technol 101:8915-8922

Geddes CC, Peterson JJ, Mullinnix MT, Svoronos SA, Shanmugam KT, Ingram LO (2010) Optimizing cellulase usage for improved mixing and rheological properties of acid-pretreated sugarcane bagasse. Bioresour Technol 101:9128-9136

Geddes R, Shanmugam KT, Ingram LO (2015) Combining treatments to improve the fermentation of sugarcane bagasse hydrolysates by ethanologenic Escherichia coli LY180. Bioresour Technol 189:15-22
Hanly TJ, Henson MA (2013) Dynamic metabolic modeling of a microaerobic yeast co-culture: predicting and optimizing ethanol production from glucose/xylose mixtures. Biotechnol Biofuels 6:44-54

Hanly TJ, Henson MA (2014) Dynamic model-based analysis of furfural and HMF detoxification by pure and mixed batch cultures of $S$. cerevisiae and S. stipitis. Biotechnol Bioeng 111:272-284

Hanly TJ, Urello M, Henson MA (2012) Dynamic flux balance modeling of S. cerevisiae and E. coli co-cultures for efficient consumption of glucose/ xylose mixtures. Appl Microbiol Biotechnol 93:2529-2541

Heer D, Heine D, Sauer U (2009) Resistance of Saccharomyces cerevisiae to high concentrations of furfural is based on NADPH-dependent reduction by at least two oxireductases. Appl Environ Microbiol 75:7631-7638

Henson MA, Hanly TJ (2014) Dynamic flux balance analysis for synthetic microbial communities. IET Syst Biol 8:214-229

Hickert LR, de Souza-Cruz PB, Rosa CA, Ayub MA (2013) Simultaneous saccharification and co-fermentation of un-detoxified rice hull hydrolysate by Saccharomyces cerevisiae ICV D254 and Spathaspora arborariae NRRL Y-48658 for the production of ethanol and xylitol. Bioresour Technol 143:112-116

Hjersted JL, Henson MA (2006) Optimization of fed-batch Saccharomyces cerevisiae fermentation using dynamic flux balance models. Biotechnol Prog 22:1239-1248

Hodge DB, Karim MN, Schell DJ, McMillan JD (2009) Model-based fed-batch for high-solids enzymatic cellulose hydrolysis. Appl Biochem Biotechnol 152:88-107

Huang R, Cao M, Guo H, Qi W, Su R, He Z (2014) Enhanced ethanol production from pomelo peel waste by integrated hydrothermal treatment, multienzyme formulation, and fed-batch operation. J Agric Food Chem 62:4643-4651

Johnsson O, Andersson J, Lidén G, Johnsson C, Hägglund T (2013) Feed rate control in fed-batch fermentations based on frequency content analysis. Biotechnol Prog 29:817-824

Kircher M (2012) How to turn industrial biotechnology into reality. N Biotechnol 29:243-247

Klinke HB, Thomsen AB, Ahring BK (2004) Inhibition of ethanol-producing yeast and bacteria by degradation products produced during pretreatment of biomass. Appl Microbiol Biotechnol 66:10-26

Ko J, Su WJ, Chien IL, Chang DM, Chou SH, Zhan RY (2010) Dynamic modeling and analyses of simultaneous saccharification and fermentation process to produce bio-ethanol from rice straw. Bioprocess Biosyst Eng 33:195-205

Konishi J, Fukuda A, Mutaguchi K, Uemura T (2015) Xylose fermentation by Saccharomyces cerevisiae using endogenous xylose-assimilating genes. Biotechnol Lett 37:1623-1630

Koppram R, Tomás-Pejó E, Xiros C, Olsson L (2014) Lignocellulosic ethanol production at high-gravity: challenges and perspectives. Trends Biotechnol 32:46-53

Lee JM, Gianchandani EP, Eddy JA (2008) Dynamic analysis of integrated signaling, metabolic, and regulatory networks. PLoS Comput Biol 4(5):e1000086

Li Y, Park JY, Shiroma R, Tokuyasu K (2011) Bioethanol production from rice straw by a sequential use of Saccharomyces cerevisiae and Pichia stipitis with heat inactivation of Saccharomyces cerevisiae cells prior to xylose fermentation. J Biosci Bioeng 111:682-686

Liu ZL (2006) Genomic adaptation of ethanologenic yeast to biomass conversion inhibitors. Appl Microbiol Biotechnol 73:27-36

Liu ZL (2011) Molecular mechanisms of yeast tolerance and in situ detoxification of lignocellulose hydrolysates. Appl Microbiol Biotechnol 90:809-825

Liu ZL, Blaschek HP (2010) Biomass conversion inhibitors and in situ detoxification. In: Vertes A, Qureshi N, Yukawa H, Blaschek H (eds) Biomass to biofuels: strategies for global industries. Wiley, West Sussex, p 27

Lopes MS (2015) Engineering biological systems toward a sustainable bioeconomy. J Ind Microbiol Biotechnol 42:813-838

Maarleveld TR, Khandelwal RA, Olivier BG, Teusink B, Bruggeman FJ (2013) Basic concepts and principles of stoichiometric modeling of metabolic networks. Biotechnol J 8:997-1008

Meng X, Ragauskas AJ (2014) Recent advances in understanding the role of cellulose accessibility in enzymatic hydrolysis of lignocellulosic substrates. Curr Opin Biotechnol 27:150-158 
Mohagheghi A, Schell DJ (2010) Impact of recycling stillage on conversion of dilute sulfuric acid pretreated corn stover to ethanol. Biotechnol Bioeng 105:992-996

Morales-Rodriguez R, Meyer AS, Gernaey KV, Sin G (2011) Dynamic modelbased evaluation of process configurations for integrated operation of hydrolysis and co-fermentation for bioethanol production from lignocellulose. Bioresour Technol 102:1174-1184

Murthy GS, Johnston DB, Rausch KD, Tumbleson ME, Singh V (2012) A simultaneous saccharification and fermentation model for dynamic growth environments. Bioprocess Biosyst Eng 35:519-534

Mutturi S, Lidén G (2014) Model-based estimation of optimal temperature profile during simultaneous saccharification and fermentation of Arundo donax. Biotechnol Bioeng 111:866-875

Nguyen TC, Anne-Archard D, Fillaudeau L (2015) Rheology of lignocellulose suspensions and impact of hydrolysis: a review. Adv Biochem Eng Biotechnol 149:325-357

Oberhardt MA, Palsson BØ, Papin JA (2009) Applications of genome-scale metabolic reconstructions. Mol Syst Biol 5:320-329

Olofsson K, Bertilsson M, Lidén G (2008) A short review on SSF-an interesting process option for ethanol production from lignocellulosic feedstocks. Biotechnol Biofuels 1(1):7

Petersson A, Lidén G (2007) Fed-batch cultivation of Saccharomyces cerevisiae on lignocellulosic hydrolyzate. Biotechnol Lett 29:219-225

Pizarro F, Varela C, Martabit C, Bruno C, Pérez-Correa JR, Agosin E (2007) Coupling kinetic expressions and metabolic networks for predicting wine fermentations. Biotechnol Bioeng 98:986-998

Rudolf A, Lequeux G, Lidén G (2007) Controlled pilot development unit-scale fed-batch cultivation of yeast on spruce hydrolysates. Biotechnol Prog 23:351-358

Sainz J, Pizarro F, Pérez-Correa JR, Agosin E (2003) Modeling of yeast metabolism and process dynamics in batch fermentation. Biotechnol Bioeng 81:818-828

Slininger PJ, Dien BS, Lomont JM, Bothast RJ, Ladisch MR, Okos MR (2014) Evaluation of a kinetic model for computer simulation of growth and fermentation by Scheffersomyces (Pichia) stipitis fed D-xylose. Biotechnol Bioeng 111:1532-1540

Straight JV, Ramakrishna D (1994) Cybernetic modeling and regulation of metabolic pathways. Growth on complementary nutrients. Biotechnol Prog 10:574-587

Sun Y, Cheng J (2002) Hydrolysis of lignocellulosic materials for ethanol production: a review. Bioresour Technol 83:1-11

Suriyachai N, Weerasaia K, Laosiripojana N, Champreda V, Unrean P (2013) Optimized simultaneous saccharification and co-fermentation of rice straw for ethanol production by Saccharomyces cerevisiae and Scheffersomyces stipitis co-culture using design of experiments. Bioresour Technol 142:171-178

Unrean P, Franzen CJ (2015) Dynamic flux balancing elucidates NAD(P)H production as limiting response to furfural inhibition in Saccharomyces cerevisiae. Biotechnol J 10(8):1248-1258

Unrean P, Khajeeram S (2015) Model-based optimization of Scheffersomyces stipitis and Saccharomyces cerevisiae co-culture system for efficient lignocellulosic ethanol production. Bioresour Bioprocess 2:1-11

Unrean P, Nguyen NH (2012) Metabolic pathway analysis of Scheffersomyces (Pichia) stipitis: effect of oxygen availability on ethanol synthesis and flux distributions. Appl Microbiol Biotechnol 94:1387-1398

Unrean P, Srienc F (2010) Continuous production of ethanol from hexoses and pentoses using immobilized mixed cultures of Escherichia coli strains. $J$ Biotechnol 150:215-223

Unrean P, Khajeeram S, Laoteng K (2015) Systematic optimization of fed-batch simultaneous saccharification and fermentation process at high-solid loading based on enzyme hydrolysis and dynamic metabolic modeling. Appl Microbiol Biotechnol. doi:10.1007/s00253-015-7173-1

Van Dyk JS, Pletschke BI (2012) A review of lignocellulose bioconversion using enzymatic hydrolysis and synergistic cooperation between enzymes - factors affecting enzymes, conversion and synergy. Biotechnol Adv 30:1458-1480

Van Zyl WH, Lynd LR, den Haan R, McBride JE (2007) Consolidated bioprocessing for bioethanol production using Saccharomyces cerevisiae. Adv Biochem Eng Biotechnol 108:205-235

Van Zyl JM, van Rensburg E, van Zyl WH, Harms TM, Lynd LR (2011) A kinetic model for simultaneous saccharification and fermentation of Avicel with Saccharomyces cerevisiae. Biotechnol Bioeng 108:924-933

Wan P, Zhai D, Wang Z, Yang X, Tian S (2012) Ethanol Production from Nondetoxified Dilute-Acid Lignocellulosic Hydrolysate by Cocultures of Saccharomyces cerevisiae Y5 and Pichia stipitis CBS6054. Biotechnol Res Int. doi:10.1155/2012/656371

Wang R, Koppram R, Olsson L, Franzén CJ (2014) Kinetic modeling of multifeed simultaneous saccharification and co-fermentation of pretreated birch to ethanol. Bioresour Technol 172:303-311

Yadav KS, Naseeruddin S, Prashanthi GS, Sateesh L, Rao LV (2011) Bioethanol fermentation of concentrated rice straw hydrolysate using co-culture of Saccharomyces cerevisiae and Pichia stipitis. Bioresour Technol 102:6473-6478

Zhang J, Lynd LR (2010) Ethanol production from paper sludge by simultaneous saccharification and co-fermentation using recombinant xylosefermenting microorganisms. Biotechnol Bioeng 107:235-244

Zhang J, Shao X, Townsend OV, Lynd LR (2009a) Simultaneous saccharification and co-fermentation of paper sludge to ethanol by Saccharomyces cerevisiae RWB222 Part I: kinetic modeling and parameters. Biotechnol Bioeng 104:920-931

Zhang J, Shao X, Lynd LR (2009b) Simultaneous saccharification and cofermentation of paper sludge to ethanol by Saccharomyces cerevisiae RWB222 Part II: investigation of discrepancies between predicted and observed performance at high solids concentration. Biotechnol Bioeng 104:932-938

Zhang M, Wang F, Su R, Qi W, He Z (2010) Ethanol production from high dry matter corncob using fed-batch simultaneous saccharification and fermentation after combined pretreatment. Bioresour Technol 101:4959-4964

Zhao X, Dong L, Chen L, Liu D (2013) Batch and multi-step fed-batch enzymatic saccharification of Formiline-pretreated sugarcane bagasse at high solid loadings for high sugar and ethanol titers. Bioresour Technol 135:350-356

\section{Submit your manuscript to a SpringerOpen ${ }^{\circ}$ journal and benefit from:}

- Convenient online submission

- Rigorous peer review

- Immediate publication on acceptance

- Open access: articles freely available online

- High visibility within the field

- Retaining the copyright to your article

Submit your next manuscript at springeropen.com 